\title{
SPEZIELLE MINERALOGIE
}

\author{
Neunte erweiterte Auflage der "Mineralogie \\ von \\ PROF. DR. R. B RAU N S \\ bearbeitet von \\ DR. KAR L F. CH U D O B
}

ord. Professor der Mineralogie und Petrographie der Universität Bonn

\section{Mit 105 Textfiguren}

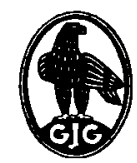

WALTER DE GRUYTER \& CO.

vormals G. J. Göschen'sche Verlagehandlun' - J. Guttentag, Verlagsbuchhandlung - Georg Reimer - Karl J. Trübner * Veit \& Comp. 
Alle Rechte, einschl, der Rechte der Herstellung von Photokopien und Mikrofilmen, von der Vorlagshandlung vorbehalten

\author{
Copyright 1955 by \\ Walter de Gruyter \& Co. \\ Berlin W 35, Genthiner Strake 13
}

Archiv-Nr. 110031

Druck von Rudolf Wendt KG., Berlin N 65

Printed in Germany 